\title{
Plants and Their Bioactive Compounds with the Potential to Enhance Mechanisms of Inherited Cardiac Regeneration
}

Authors

Affiliations
Zhen Zhou ${ }^{1}$, Dianbin $\mathrm{Li}^{2}$, Hua Zhou ${ }^{3}$, Xiaoli Lin ${ }^{1}$, Censing Li ${ }^{4}$, Mingfeng Tang ${ }^{1}$, Zhou Feng ${ }^{3}$, Ming Li ${ }^{1}$

${ }^{1}$ Laboratory of Innovative Medicine, Hong Kong

2 Emergency Department, Tianshan Chinese Medicine Hospital, Shanghai, China

${ }^{3}$ Department of Cardiology, Shuguang Hospital, Shanghai University of Traditional Chinese Medicine, Shanghai, China

${ }^{4}$ Queen Mary University of London, London, UK

\section{Key words}

- natural plant compounds

- cardiovascular diseases

- myocardial regeneration

- mechanisms of inherited cardiac regeneration

- cardiovascular diseases

- cardiogenin received July 28,2014

revised March 20, 2015

accepted March 23, 2015

Bibliography

DoI http://dx.doi.org/

10.1055/s-0035-1545946

Published online May 27, 2015

Planta Med 2015; 81: 637-647

(C) Georg Thieme Verlag KG

Stuttgart - New York .

ISSN 0032-0943

\section{Correspondence}

\section{Dr. Ming Li}

Laboratory of Innovative

Medicine

22/F, Hang Lung Center

2-20 Paterson Street

Causewaybay

Hong Kong S. A. R.

Phone: +85297363681

Fax: + 85226961099

li.ming@labinnovativemedicine. com

\section{Abstract}

$\nabla$

This article reviews the current progress and research indications in the application of natural plant compounds with the potential for the treatment of cardiovascular diseases. Our understanding of how to apply natural plant compounds to enhance mechanisms of inherited cardiac regeneration, which is physiologically pertinent to myocyte turnover or minor cardiac repair, for substantial cardiac regeneration to repair pathological heart injuries is discussed. Although significant progress has been made in the application of natural plant compounds for therapy of heart diseases, the understanding or the application of

\section{Introduction}

$\nabla$

Cardiovascular disease (CVD) is a class of diseases caused mainly by disorders of the heart and blood vessels, including coronary heart disease (CHD), congenital heart disease, arrythmias, heart failure, cardiomyopathy, aorta disease, and peripheral artery disease [1,2]. CVD is the leading cause of death around the world. Due to worldwide population growth and an increasing elderly population, the death toll of CVD increases each year and is estimated to reach 23 million by 2030 according to the World Health Organization [3]. Among all types of CVD, CHD is the most common one that accounts for one-third of the total CVDrelated deaths [4]. CHD results from partial or complete occlusion of the coronary artery and subsequent cardiac ischemia in the affected territory. Complete occlusion of the coronary artery leads to a massive loss of cardiac tissues, including cardiac myocytes and coronary vasculature in the distribution territory of the affected artery $[5,6]$. Conventional treatments for CHD, including medication (e.g., beta-blockers, diuretics, etc.) and surgical intervention (e.g., angioplasty, coronary these compounds specifically for enhancing mechanisms of inherited cardiac regeneration for the treatment of cardiovascular diseases is little. Recent recognition of some natural plant compounds that can repair damaged myocardial tissues through enhancing mechanisms of inherited cardiac regeneration has offered an alternative for clinical translation. Application of natural plant compounds, which show the activity of manipulating gene expressions in such a way to enhance mechanisms of inherited cardiac regeneration for cardiac repair, may provide a promising strategy for the reconstruction of damaged cardiac tissues due to cardiovascular diseases.

artery bypass grafting), can only alleviate symptoms and slow down the deterioration of the disease without pathological modifying effects [7]. Although heart transplantation may serve as a final resort for end-stage heart failure patients, it is not only costly, but also limited by donor availability and host immune rejection. Recent striking advances in stem cell research and regeneration medicine have provided the hope for therapeutic cardiac repair through cell transplantation-based strategies. Stem cells of particular interest include embryonic stem cells (ESCs) $[8,9]$, induced pluripotent stem cells (iPS) $[10,11]$, bone marrow-derived mesenchymal stem cells (MSCs) $[12,13]$, and umbilical cord blood cells $[14,15]$. However, there is still a long way to go before the successful clinical translation of stem cell transplantation-based therapy due to the yet to be solved drawbacks and complications, including host immune rejection, risk of tumorigenesis, and low cardiogenic efficiency.

Thus, searching for alternative strategies for an effective treatment of CVD has attracted increasing research interest, especially following the recent discovery of the inherited ability of heart regener- 
ation in the adult mammalian heart [16-19]. With the growth of our understanding, it was soon realized that mechanisms of inherited cardiac regeneration pertinent to heart homeostasis and possible minor cardiac injury repair are far from effective for the repair of pathological damages of the heart $[14,15]$. Nonetheless, the realization of this limitation hints for an alternative strategy for substantial treatment of CVD through enhancing the inherited cardiac regeneration ability. This review is dedicated to the emerging research topic on how natural plant compounds can be used to enhance mechanisms of inherited cardiac regeneration for effective treatment of injured hearts due to CVD.

\section{Mechanisms of Inherited Cardiac Regeneration}

$\nabla$

Cardiac regeneration capacity is largely retained throughout the lifespan in lower vertebrates, such as amphibians and fish [2022 ]. By contrast, mammals still retain some cardiac regeneration capacity at their neonatal stage, which is then lost shortly after birth [23]. The classic dogma that the adult mammalian heart is a post-mitotic organ without renewal ability has preset the field for decades $[24,25]$. However, this traditional view has been challenged by increasing new research findings that the adult mammalian heart still contains limited renewal ability. BrdU incorporation experiment in a rat model demonstrated a descending trend of BrdU positive cells in the heart throughout the whole life span from $\sim 37 \%$ on day 3 to $\sim 11 \%$ on day $5, \sim 5 \%$ on day 13 after birth, and $0.2 \sim 2 \%$ in an adult [26].

Growing data supporting this new concept that the adult mammalian heart contains limited renewal ability have been documented for human hearts $[27,28]$. Using incorporated ${ }^{14} \mathrm{C}$ in DNA obtained from human adult hearts, Bergmann et al. provided direct evidence that human adult myocytes continue to regenerate during the whole lifetime, though the capacity for myocyte regeneration decreases with age [29]. It was soon found that a subpopulation of replicating myocytes was preserved in the postnatal, adult, or senescent heart with the ability of repopulating parenchymal myocytes [27,30-33]. The existence of cardiac resident stem cells (CSCs), in line with stem cell criteria of self-renewing, clonogenic, multipotent, giving rise to myocytes, smooth muscle, and endothelial cells, was demonstrated [34-39]. These identified CSCs were further grouped according to their surface markers, such as c-kit, Sca-1, Isl1, and MDR1 positive cells. Of them, the c-kit and Sca-1 positive CSCs were identified as the predominant CSC subpopulations in the heart stem cell pool [35, $36,40]$. These CSCs are likely involved in the cell turnover-mediated cardiac cell (e.g., myocytes, smooth muscle cells, and vessel endothelial cells) replacement and possible cardiac minor repair during myocardial homeostasis $[31,33,35,36,40,41]$. Consistent with this notion, the number of CSCs increased significantly in response to myocardial infarction (MI) [42] and the application of c-kit-positive CSCs produced a substantial engraftment and regenerated cardiac tissues in an MI animal model $[31,43]$. In the physiological condition of human adult life, the death rate of myocytes during cardiac homeostasis accounts for the loss of $\sim 3 \times 10^{6}$ myocytes per day, which is putatively a close match to that of regenerated myocytes through mechanisms of inherited cardiac regeneration [15]. Unfortunately, this ability to repopulate the lost myocytes during cardiac homeostasis is severely limited in pathological cardiac repair [15]. Therefore, maneuvers to enhance mechanisms of inherited cardiac regeneration would accomplish the aim for substantial treatment of CVD.

\section{Plant Compounds Used to Enhance Cardiac Angiogenesis and Myocardial Regeneration $\nabla$}

As aforementioned, current available strategies for the treatment of CVD, including drugs, surgical interventions, and cell transplantation-based therapies, have their innate limitations, some of which even cause severe or life-threatening complications. Therefore, the development of more effective and safer strategies for substantial treatment of CVD is highly desirable. In light of the newly discovered mechanisms of inherited cardiac regeneration and the realization of its low efficiency in pathological cardiac repair, it is reasonable to postulate that maneuvers that can enhance mechanisms of inherited cardiac regeneration could potentially achieve pathology-modifying and functional repair of diseased heart.

To potentiate such repair of a diseased heart, the creation of an inductive microenvironment for cardiogenesis in the territory is a corequisite [15]. The requirement of an inductive microenvironment for cardiogenesis, such as timely delivery of oxygen, necessary nutrients, variants of growth factors, and circulating stem cells to the territory, must be satisfied in order for cell trafficking, survival, growth, and differentiation in the previously deprived region. Therefore, rapid reconstitution of the damaged vasculature in the territory is primarily vital for the creation of such an inductive microenvironment for any myocardial regeneration. For substantial repair of acute cardiac injury, such as MI, replacement of the dead cardiac tissues with newly regenerated myocardium is a therapeutic ideal. Only under such an aforementioned cardiogenesis-inductive microenvironment may myocardial regeneration be fulfilled through enhanced (i) proliferation and differentiation of resident CSCs; (ii) or/and cardiogenic differentiation of bone marrow-derived circulating stem cells that migrate to the site of damage; (iii) transient dedifferentiation and proliferation of terminally differentiated myocytes under defined conditions.

One such maneuver that can help create such a cardiogenesis-inductive microenvironment and promote cardiogenesis is natural plant compounds with known functions, such as traditional Chinese medicinal herbs that are related to cardiac regeneration. Although this is an emerging research field, several research teams, including our laboratory, have already made significant progress with promising findings. Listed below are several such examples of these natural plant compounds with potential for substantial cardiac regeneration.

\section{The Beneficial Effects of Rehmannia glutinosa on Cardiac Angiogenesis and Cardiogenesis $\nabla$}

Rehmannia glutinosa ( $R$. glutinosa, also known as Dihuang), a member of the Scrophulariaceae family, is a well-known traditional Chinese medicine widely used in Asian societies [44]. The safety of $R$. glutinosa administration has been proven by its practice in traditional medicine over thousands of years. Due to its beneficial effects on Yin and the kidney, R. glutinosa has been used commonly for the treatment of diseases associated with hypodynamia. In the last several decades, studies have shown that $R$. glutinosa has multiple functions in the cardiovascular system $[45,46]$, though the underlying molecular mechanisms are yet to be revealed.

Some research results demonstrated that $R$. glutinosa extract (RGE) may exert its specific effect on hematogenesis in mice by 
enhancing proliferation and differentiation of bone marrow-derived hematopoietic stem cells [47]. Other recent studies reported that the oral administration of RGE (1-1.5 g/ $/ \mathrm{kg} /$ day) to MI model rats not only increased the quantities of endothelial progenitor cells (EPCs), potential targets for cardiac repair, both in blood and in bone marrow, but also promoted their mobilization to peripheral blood, migration to injured heart tissues, and activation of their function for angiogenesis [48]. It was further found that RGE $(25-50 \mu \mathrm{g} / \mathrm{ml}$ culture medium) could also stimulate EPC proliferation, migration, and capillary-like tube formation, probably through the activation of the stromal-derived factor- $1 \alpha /$ receptor (SDF- $1 \alpha /$ CXCR4) cascade [48].

Other angiogenesis-associated factors, such as vascular endothelial growth factor receptor 2 (VEGFR2) and CD133 (a hematopoietic stem and progenitor cell marker), were also upregulated by RGE. These properties of RGE may help create a cardiogenesis inductive microenvironment in the territory of cardiac damage that favors the ensuing myocardial regeneration.

In addition to the potential angiogenic effect of RGE, the activity of RGE in the prevention of caspase- 3 activation-induced cardiac myocyte death in vitro, probably by increasing Bcl-2 expression and inhibiting Bax expression, was also suggested [49]. More importantly, RGE treatment could lead to significant functional improvement in the chronic stage after acute MI including an increased left ventricle eject fraction, a reduced ischemic area, and a decreased apoptotic index in the infarct myocardium. Despite the fact that the chemical compositions of RGE await further clarification, these findings render RGE a promising candidate for further drug development towards the treatment of CVDs.

\section{The Multi-Beneficial Effects of Ginseng on Cardiovascular Disease \\ $\nabla$}

Ginseng, a member of the Araliaceae family, is one of the most well-known and wildly used herbal medicines around the world. It is routinely used for the general human well-being and is considered to have multi-beneficial effects on pathological conditions and diseases related to the immune system, endocrine system, central nervous system, and cardiovascular system [50-52]. During the past few decades, an increasing application of ginseng has been observed not only in oriental society, but also in Western countries. There are various species of ginseng, among which Asian ginseng (Panax ginseng) and North American ginseng (Panax quinquefolius) are the two major ones $[53,54]$. Ginseng reportedly contains multiple active constituents, including ginsenosides, quinquefolans, polysaccharides, pyridoxine, and fatty acids [55]. Among them, ginsenosides are considered to be the main active compounds that are attributed to the multi-beneficial effects of ginseng $[54,56]$. Ginsenosides are a special group of triterpenoid saponins that are found almost exclusively in Panax species (ginseng), and up to now, more than 150 naturally occurring ginsenosides have been isolated from roots, leaves/stems, fruits, and/or flower heads of ginseng. The protopanaxadiol (e.g., $\mathrm{Ra} 1$ and $\mathrm{Rb} 1$ ) and protopanaxatriol groups (e.g., $\operatorname{Rg} 1$ and $\mathrm{Re}$ ) are the two main groups of ginsenosides ( $\bullet$ Fig. $\mathbf{1}$ a, b). The considerable variety of ginsenosides and their multiple functions make it hard to dissect out their individual functions. Nevertheless, extensive investigations of several major ginsenosides were performed, owing to a renewed interest in exploring the mechanistic nature underlying ginseng's beneficial effects for possible novel drug development.
$\operatorname{Rg} 1$, one of the most active compounds isolated from ginseng, has attracted many research interests. In vitro studies on human umbilical vein endothelial cells (HUVECs) demonstrated that Rg1 treatment significantly promoted the migration, proliferation, and capillary-like tube formation of the cultured HUVECs [5759]. Downregulation of microRNA-214 and microRNA-15b, which in turn leads to increased VEGFR-2 expression, was suggested to underlie Rg1-induced angiogenesis [60,61]. Consistent with these in vitro results, some in vivo studies demonstrated that Rg1 could improve cardiac function, reduce infarct size, and increase capillary density in the infarct area of a rat MI model and in a transverse aortic constriction-induced left ventricular hypertrophy model, probably through upregulating expressions of vascular endothelial growth factor (VEGF), CD31, and hypoxia inducible factor- $1 \alpha$ (HIF-1 $\alpha$ ) [62,63]. Moreover, further in vitro studies found that $\operatorname{Rg} 1$ exerted a significant effect on preventing apoptosis $[62,63]$. Consistent with these findings, it was reported that Rg1 could reduce apoptosis of cultured H9c2 cardiomyocytes [64] and dose-dependently increase cell viability in a cardiomyocyte hypoxia/reoxygenation model [65].

$\mathrm{Rb} 1$, another major ginsenoside isolated from ginseng, also showed a protective effect of cardiomyocytes from apoptosis [66-68]. Some studies indicated that the PKA signaling pathway and caspase-9 pathway might be involved in an Rb1-mediated antiapoptotic effect [69]. Many other investigations with myocardial remodeling, cardiac ischemia and reperfusion, angiogenesis, and cardiomyopathy animal models also consistently demonstrated the cardiovascular beneficial effects of Rg1 and Rb1 [7073]. Therefore, it would be highly rewarding to investigate whether ginsenosides can enhance cardiogenesis in the adult mammalian heart under both physiological and pathological conditions.

\section{The Application of Salvia miltiorrhiza Bunge and its Isolated Compounds for the Treatment of Cardiovascular Disease \\ $\nabla$}

Salvia miltiorrhiza Bunge (S. miltiorrhiza Bunge, Danshen in Chinese), a member of the Labiatae family, is extracted from the dried root of a perennial plant, S. miltiorrhiza Bunge, and is widely used for promoting blood circulation and removing blood stasis in Chinese herbal medicine practice. Cardiovascular beneficial effects of $S$. miltiorrhiza Bunge whole extract have been studied extensively. These studies showed that S. miltiorrhiza Bunge could promote angiogenesis, protect cardiomyocytes against ischemia-induced apoptosis, and enhance the transdifferentiation of MSCs into cardiomyocytes [74-78]. Due to its various cardiovascular beneficial effects, $S$. miltiorrhiza Bunge has been commonly used for the clinical treatment of CVD in China.

To date, more than 80 chemical components, including watersoluble phenolic acids and lipophilic tanshinones, have been identified and isolated from S. miltiorrhiza Bunge [78,79]. The main lipophilic compounds from S. miltiorrhiza Bunge include tanshinone I ( $\tan$ I), tanshinone IIA ( $\tan$ IIA), tanshinone IIB (tan IIB), and cryptotanshinone, while the major hydrophilic compounds include salvianolic acid A, salvianolic acid B, danshensu, and protocatechuic aldehyde.

Tan IIA ( $\odot$ Fig. 1 c) is one of the most abundant and active lipophilic diterpenes found in S. miltiorrhiza Bunge. Multiple beneficial effects of tan IIA, including antioxidant, anti-inflammatory, antiapoptosis, and proangiogenic effects, have been demonstrat- 
Protopanaxadiol group

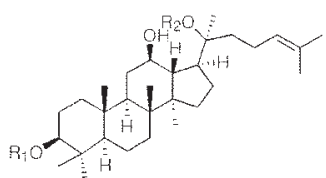

Protopanaxatriol group

b

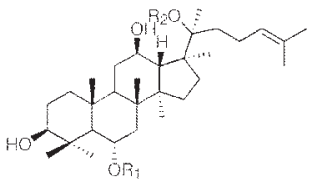

Tanshinone IIA ( $\tan$ IIA)

c<smiles>Cc1ccc2c(c1)C(=O)c1c(C)cccc1C2=O</smiles>

Astragaloside IV

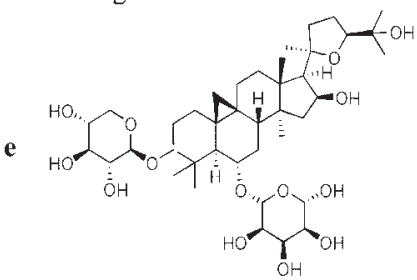

Salvianolic acid B

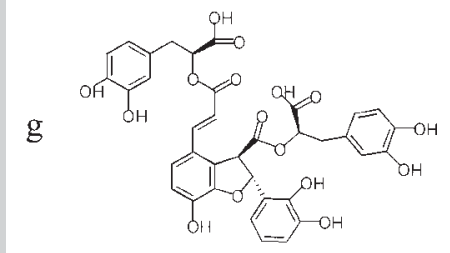

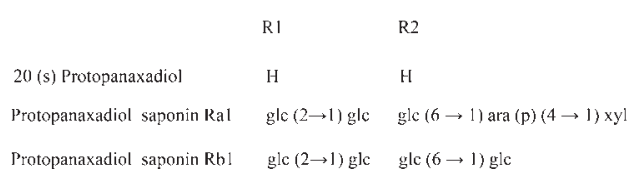

$\begin{array}{lll} & \text { R1 } & \text { R2 } \\ \text { 20 (s) Protopanaxatriol } & \text { H } & \text { H } \\ \text { Protopanaxatriol saponin Re } & \text { glc }(2 \rightarrow 1) \text { rlaa } & \text { glc } \\ \text { Protopanaxatriol saponin Rg! } & \text { glc } & \text { glc }\end{array}$

Sodium tan IIA sulfonate

d<smiles></smiles>

Salvianolic acid A

f

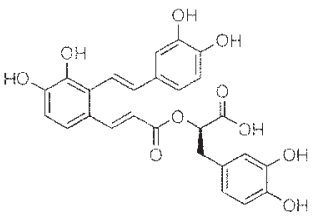

Cardiogenin (Niga-ichigoside F1)

h
Fig. 1 Chemical structures of the cited compounds isolated, respectively, from ginsenosides, S. miltiorrhiza Bunge and G. japonicum Thunb. vax. chinense F. Bolle. ed $[80,81]$. As a result, tan IIA has long been used effectively to prevent and treat various CVD clinically in China. Although the precise mechanisms underlying the effects of tan IIA await more detailed and systematic experimental and clinical studies, recent studies have started to uncover some interesting beneficial effects of tan IIA on the cardiovascular system.

It has been found that tan IIA can improve the local microenvironment of a damaged heart area through promoting angiogenesis. Studies using rat MI models showed that administration of tan IIA resulted in improved cardiac function, reduced infarct size presumably through upregulating VEGF expression, and consequent angiogenesis [82]. Further studies also consistently demonstrated that treatment of acute MI animals with a water-soluble derivative of tan IIA, sodium tan IIA sulfonate ( $\bullet$ Fig. 1 d), significantly reduced the infarct size and decreased the number of apoptotic cardiomyocytes in the infarct zone [83].

In a heart failure rat model induced by thoracic aorta constriction, tan IIA injection for 12 weeks decreased myocardial apoptosis, assessed by the TUENL method, likely through upregulating the mRNA and protein levels of Bcl-2 and miR-133 [84]. Regulation of miR-133 levels by tan IIA was further confirmed in cultured neonatal cardiomyocytes under hypoxic condition showing that tan IIA treatment increased the miR-133 level by activating the MAPK ERK1/2 pathway [85]. Using both in vitro and in vivo studies, Fu et al. showed that tan IIA could protect myocytes against apoptosis triggered by oxidative stress involving $\mathrm{Bcl}-2$ regulation [80]. The mechanism underlying the action of $\tan$ IIA in preventing cardiac apoptosis is presumably via regulation of the ratio of $\mathrm{Bcl}-2 / \mathrm{Bax}$ [86] and downregulating of the miR-1 level $[87,88]$.

Interestingly, recent evidences indicated that tan IIA could also enhance the migration of bone marrow MSCs to the infarct region following MI $[89,90]$. As mentioned above, both endogenous and transplanted MSCs can improve cardiac functions after MI, though with limited efficacy, by transdifferentiation into cardiomyocytes directly and/or through the paracrine mechanism indirectly. Tong et al. showed that combination treatment of tan IIA and MSCs in a rat MI model exhibited better effects than that with MSCs alone in terms of infarct size reduction and cardiac function improvement [89]. Tan IIA treatment significantly increased the number and the survival rate of MSCs in the infarct region, likely through the upregulation of the SDF-1/CXCR4 axis, which is essential for tan IIA to enhance the recruitment of MSCs to the infarct zone [89]. Consistent with this finding, using both 
in vitro experiments and a rat acute MI model, Xie et al. [90] reported that treatment of tan IIA and astragaloside IV ( $\bullet$ Fig. 1 e) could promote the migration and homing of exogenous MSCs to the ischemic region, at least partially, through the upregulation of CXCR4 expression.

Besides tan IIA, some other compounds isolated from S. miltiorrhiza Bunge also showed cardioprotective activities. For example, salvianolic acid A and salvianolic acid B ( Fig. 1f,g) could enhance angiogenesis both in vitro and in rat MI models [91-93]. Mechanistic studies in a rat MI model showed that salvianolic acid A enhanced ischemia-induced angiogenesis, likely by upregulating VEGF and VEGFR-2 levels, and promoting the migration and vasculargenesis of EPCs [91]. Recent studies further indicated that the extract of $S$. miltiorrhiza Bunge not only promoted angiogenesis and protected cardiomyocytes against ischemia-induced apoptosis, but also enhanced the transdifferentiation of MSCs into cardiomyocytes [74-78] and myocardial regeneration in the infarct zone in MI animal models (authors' unpublished data). Although S. miltiorrhiza Bunge has been commonly used for the treatment of CVD based on its various cardiovascular beneficial effects, the dissection of the effect of individual compounds of $S$. miltiorrhiza Bunge remains to be elucidated due to the complexity of its extract.

\section{Potentiating Mechanisms of Inherited Cardiac Repair for the Treatment of Cardiovascular Disease by Geum japonicum \\ $\nabla$}

Several recent studies have demonstrated that an organic extract of Geum japonicum Thunb. vax. chinense F. Bolle (EGJ) exerted dual actions on angiogenesis and myogenesis leading to the substantial repair of infarct hearts and damaged muscles in animal models $[13,94,95]$. Two active fractions (Angio-T \& AFGJ), isolated from EGJ, showed remarkable activities in promoting the growth of coronary collateral vessels in CHD rat models [96,97]. The most significant merits of these studies are the clear demonstrations of the types, densities, and distribution of the newly grown coronary collaterals in the ischemic heart [97]. The results showed that AFGJ, which is mainly comprised of polyphenols, could significantly induce the growth of small coronary arteries, including arterioles $(21-63 \mu \mathrm{m})$ and microarteries $(63-210 \mu \mathrm{m})$, in ischemic hearts. The densities of the arterioles and the microvesesles in the hearts of AFGJ-treated animals were significantly higher than those in the hearts of the vehicle-treated group $\left({ }^{*} \mathrm{p}<0.05\right.$; $\odot$ Fig. 2A, B) [97]. However, the densities of vessels (with diameters less than $21 \mu \mathrm{m}$ or greater than $210 \mu \mathrm{m}$ ) showed no significant difference between the two groups. The 2D evaluation of the unit area of vessels in ROI showed that the average density of vessels of AFGJ-treated hearts was significantly higher than that of the vehicle-treated hearts $\left({ }^{* * *} \mathrm{p}<0.001\right)$. More interestingly, quantitative volumetric measurements of heart vascular angiogenesis demonstrated that both the values of vascular volume (VV) and total volume (TV) in AFGJ-treated ischemic hearts

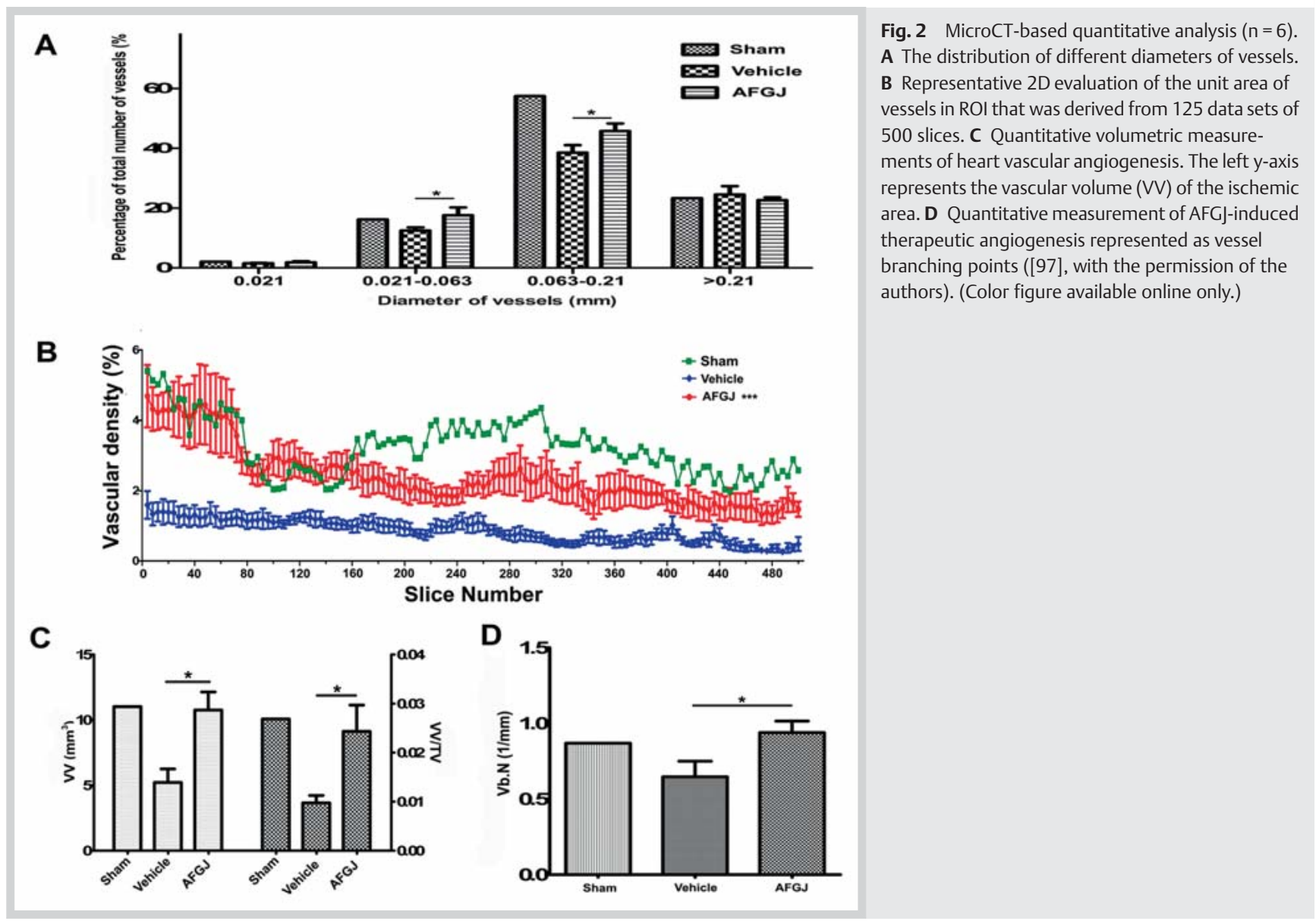


were significantly increased compared with those in the vehicletreated hearts ( $\left.{ }^{*} \mathrm{p}<0.05\right)$, and were virtually close to those of the nonischemic hearts in the sham operated group (mean: 10.754 vs. 11.020 and 0.024 vs. 0.027 ), indicating that AFGJ treatment effectively reconstituted the lost coronary vessels due to infarction, especially the microvessels in the ischemic region of the hearts (॰ Fig. 2C). More importantly, an analysis of a number of intersections between vessel and non-vessel components per total length (vb. N) of vessels in volume of interest (VOI), which can provide information on vessel branching points, demonstrated that substantially more branching points in the AFGJ-treated heart compared with those in the vehicle-treated heart (mean \pm SEM: $0.9392 \pm 0.07615$ vs. $0.6462 \pm 0.1036$; ${ }^{*} \mathrm{p}<0.05$ ), implying the formation of new substantial collateral vessels in AFGJ-treated ischemic hearts ( Fig. 2D). Both the quantitative MicroCT and quantitative histological analysis results consistently demonstrated the significantly increased vascular density and collateral branching points in the ischemic region of AFGJ-treated hearts. MicroCT analysis also provided visible evidence of the vascular network of the experimental hearts.

Taken together, AFGJ appears to promote therapeutic angiogenesis through the induction of growth of new coronary collaterals (with diameter $0.021-0.21 \mathrm{~mm}$ ) in adult ischemic hearts. AFGJinduced growth of new collaterals in ischemic hearts is of therapeutic significance evidenced by the improved functional performance of the CHD hearts. More importantly, AFGJ-induced growth of coronary collaterals into the ischemic region of CHD hearts should address the root pathology of the disease and provide a novel therapeutic method for effective/curative treatment of chronic CHD.

In addition to the effect of EGJ or AFGJ on the stimulation of substantial growth of coronary collateral vessels in ischemic hearts, several other studies also demonstrated that another active fraction identified/isolated from EGJ showed the property in stimulating myocardial regeneration in an acute MI animal model through topical injection $(0.3 \mathrm{mg})$ or intragastric administration (300-500 mg/kg body weight) $[13,94,98,99]$. These findings prompted further investigations for the identification and isolation of the active component from the fraction and demonstration of the activity of the active component. Consequently, a car-

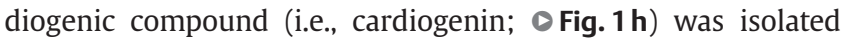
from the active fraction with activities in enhancing cardiogenic differentiation efficiency of MSCs and regenerating myocardial tissues in MI animal models $[13,98,99]$. These remarkable results showed that both the active fraction and cardiogenin can promote cardiogenic differentiation of MSCs in culture with approximately $40-50 \%$ of the cultured MSCs elongated, forming rod-like phenotypes with MEF2 (3-day treatment) or MHC (7-day treatment) positively stained. More importantly, the indication of the effect of the active fraction or cardiogenin in promoting cardiogenic differentiation of MSCs in vitro can be translated into regeneration of a substantial amount of myocyte-like cells with colocalized ki67 positive nuclei and MHC positive cytoplasm observed throughout the whole infarct region in vivo, which should contribute to the significantly improved cardiac function $[13,99]$. These newly regenerated myocytes replaced the dead cardiac tissues. Computated planimetric analysis demonstrated that the scar area of the hearts in the active fraction or cardiogenin-treated MI hearts were approximately $1 / 4-1 / 2$ smaller than that in the vehicle-treated rats $(\mathrm{p}<0.01)$.

The identification of male cardiac cells in female donor hearts, which were transplanted to male recipients, raised the thought that these male cardiac cells might be the progeny of circulating stem cells of the recipient's bone marrow origin [100,101]. Some recent studies have also shown agreeable evidences for the active participation of bone marrow-derived MSCs in myocardial regeneration $[13,96,99]$. In these studies, it was found that although bone marrow-derived MSCs can migrate to the infarct zone after acute MI, their cardiogenic differentiation efficiency is too low to produce meaningful repair to the damaged heart. The experiment using cardiogenin to treat MI rats that were subjected to bone marrow transplantation of labeled MSCs prior to MI production provided evidence that considerable bone marrow-derived MSCs participated in myocardial regeneration $[13,96,99]$. Many vessels (yellow-circled) and DiI- (orange-labeled cytoplasm) MEF2 (red-stained nuclei) colocalized cells (green-circled) were observed throughout the infarct zone ( $\bullet$ Fig. 3 ). Some of the myocyte-like cells in the central infarct zone (blue arrows), which were positively stained by both Ki67 (nuclei) and MHC (cytoplasm), were found with some of Ki67 positive nuclei of the vessel endothelial cells observed (green arrows). The normal myocytes along the infarct rim were MHC positive, but Ki67 negative (red circles). Some of the regenerating myocytes joined together in tandem forming myocardium-like tissue (blue arrows). The importance of these studies is the demonstration that endogenous MSCs could be an important progenitor cell pool for regeneration of new myocardium on the condition that their cardiogenic differentiation potential is triggered. The supreme weight of using natural plant compounds to potentiate mechanisms of inherited cardiac repair for treatment of cardiac damage in these studies is that activation of endogenous stem cells by natural plant compounds for repair of impaired hearts would eliminate the possible teratoma formation, immunorejection reaction, and many other possible complications that are associated with the use of ESCs or other exogenous progenitor cells [102-105]. The mechanistic study indicated that cardiogenin or the active fraction derived from EGJ may interact with $G$ proteins initially, which subsequently trigger the sequential cascade of cardiogenic differentiation-associated intracellular events, such as suppression of miRNA-9 expression, which consequently upregulates its target genes, including the $\mathrm{G}$ protein family, zinc finger proteins, E-cadherin, and other growth factors such as BMPs, TGF $\beta$, FGF, and EGF to a level sufficient for an enhanced cardiogenic differentiation efficiency of MSCs and myocardial regeneration [13,99].

\section{Cardiac Repair by the Active Fraction Isolated from Rosa laevigata Michx \\ $\nabla$}

The total flavonoids (TFs) and some other compounds isolated from Rosa laevigata Michx fruit have been reported to have a potent antioxidant activity in both in vitro and in vivo experiments $[106,107]$. These studies showed that TFs not only exhibited a high scavenging effect, but also significantly decreased the levels of total blood cholesterol (45.02\%), triglycerides (33.86\%), and low-density lipoprotein cholesterol (73.68\%) in a hyperlipemia mouse model [107]. The authors therefore inferred that the properties of TFs in antioxidant and hypolipidemic activities might render TFs a potential medicine for CVD.

A recent study from our laboratory has again demonstrated the ability of an active fraction isolated from the Chinese herb $R$. laevigata Michx (i.e., aFRLM) in promoting myocardial regeneration in an acute MI rat model. It was found that daily oral administration of aFRLM (300 mg/kg body weight) to an acute MI ani- 


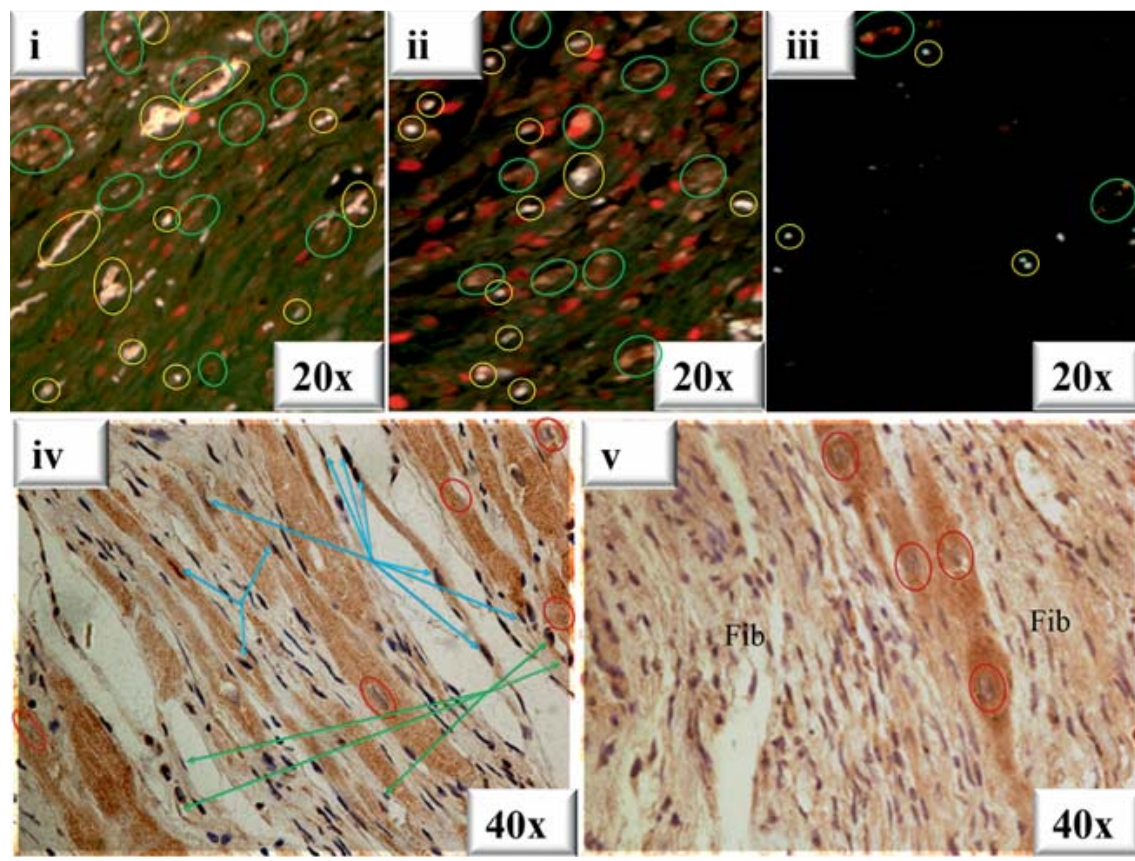

Fig. 3 The possible cellular origin of the regenerating myocytes. Representative counter-staining (Dil and MEF2) micrographs of the MI heart, which was subject to BMT with Dil-labeled MSCs 1 week prior to LAD ligation. i One week post-cardiogenin treatment. ii Two weeks post-treatment, significantly more MEF2 positive cells colocalized with the Dil labeling (green circles) were found. iii There were less vessels (yellow circles) and Dil-MEF2 colocalized cells (green circles) observed in the vehicletreated heart. iv Ki67 and MHC double immunostained LV section of the cardiogenin-treated heart. Blue arrows, newly formed myocyte-like cells. Green arrows, Ki67 positively stained vessel endothelial cells. Red circles, the normal myocytes with MHC positively, but Ki67 negatively stained. $\mathbf{v}$ Ki67 and MHC double immunostained LV section of the vehicle-treated control heart. Fibrous scar replacement (Fib) ([99], with the permission of the authors). (Color figure available online only.)

mal for a month progressively improved the cardiac function of the experimental animals. Morphological analysis of the therapeutic effect of aFRLM on MI demonstrated that the infarcted cardiac tissues were replaced by many well-arranged, red-stained myocyte-like cell clusters in the central infarct zone. By comparison, a large area of fibrous scar was found throughout the whole infarct region in the vehicle-treated MI heart with few myocytelike cell clusters observed. The result of Masson's trichrome staining further demonstrated that although the infarcted cardiac tissues were replaced by blue-stained fibrous scar tissues, many red-stained myocyte-like cell clusters were found in the central infarct region. By contrast, in the vehicle-treated MI heart, the blue-stained fibrous scar replacement of the infarcted cardiac tissues was found throughout the whole infarcted region with few red-stained myocyte-like cells clusters observed. Some of the myocyte-like cells were positively stained by both Ki-67 (brown nuclei) and MHC (yellow cytoplasm) specific antibodies in aFRLMtreated MI hearts. Some of the regenerating myocytes joined together in tandem forming myocardium-like tissue. By contrast, fibrous scar replacement was found throughout the infarct region with few Ki-67 and MHC positively stained myocyte-like cells found ( Fig. 4) (author's unpublished data). Although the cellular origin of the regenerating myocytes remains to be verified, based on the ability of aFRLM ( $40 \mu \mathrm{g} / \mathrm{ml}$ culture medium) to induce cardiogenic differentiation of MSCs (20-30\%) in vitro, and the one-third smaller sizes of the newly regenerated cardiac myocytes in aFRLM-treated MI hearts, the regenerating myocytes are likely derived from circulating MSCs or CSCs [108-110]. Occlusion of a major coronary artery would cause a significant loss of functional cardiac myocytes in its distribution territory through necrosis, intrinsic and extrinsic apoptosis pathways, and autophagy. Repair of the dead cardiac tissues with newly regenerated cardiac myocytes remains a mission impossible. Therefore, this report may provide an alternative method for the repair of infarct hearts through enhancing mechanisms of inherited cardiac repair.

\section{Conversion of Fibroblasts in Cardiac Scar into Myocytes by Natural Plant Compounds \\ $\nabla$}

Although in fetal life the ability of regeneration of tissues to repair wounds is retained with no scar tissue formed, in postnatal life, wound healing occurs at the expense of function with a fibrous scar formed to repair the wound [111]. MI is naturally repaired by the formation of a fibrous scar that patches up the cardiac wound, sustaining the integrity of the heart. However, the scars are mainly composed of disordered fibrous tissues having no resemblance to the original cardiac tissues being replaced. Therefore, although the integrity and about $70 \%$ of the strength of the affected myocardium is attained, the scar tissues are not functional, which may eventually cause heart failure [112]. Therefore, conversion of the cardiac fibroblasts in the scar tissues into myocytes may be an ideal alternative for the treatment of chronic MI.

Although conversion of fibroblasts in heart scar tissues into myocytes would be a very intriguing therapy for the disease, solid supporting evidences are few. A recent study reported that the introduction of a combination of Gata4, Mef2c, and Tbx5 genes into cardiac resident fibroblasts (CRFs) could convert them into cardiac myocyte-like cells both in vitro and in vivo $[113,114]$. A subsequent study from another laboratory soon reported that the conversion of CRFs by this combination of transcription factors was not only inefficient, but also resulted in decreased cell survival in vivo [115]. Some other studies indicated that delivery of TGF $\beta$ or MyoD into CRFs may convert them into myocyte phenotypes $[116,117]$. Compared with the method associated with gene combination delivery, treatments with natural compounds, such as a drug-like small molecule or compound combination, that can manipulate expressions of cardiac differentiation-associated genes or a gene combination, such as MEF2, GATA4, and TBX5 in treated CRFs, would be more convenient and practical alternatives, so that when the drug-like molecule or compound combination is administered, the drug-like molecule-mediated actions may override the post-mitotic phenotype of the fibroblasts in the scar tissues and covert them into cardiac myocytes. 

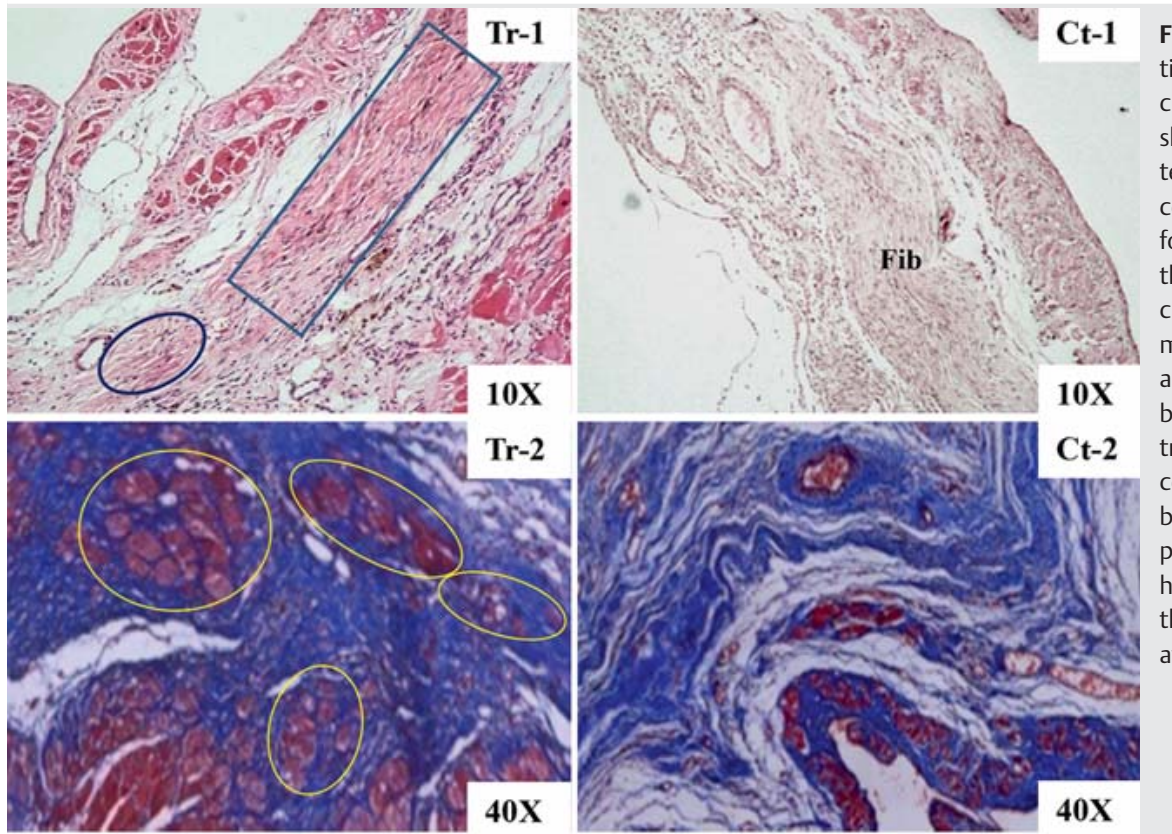

Fig. 4 Morphological assessment of the therapeutic effect of aFRLM on MI. Tr-1, representative micrographs of the aFRLM-treated (4 weeks) MI heart showing many red-stained myocyte-like cell clusters (blue rectangular surrounded) formed in the central area of the infarct. Ct-1, a fibrous scar was found throughout the whole infarct region (Fib) in the vehicle-treated MI heart. Tr-2, Masson's trichrome staining demonstrated the formation of many red-stained myocyte-like cell clusters in the aFRLM-treated heart (yellow-circled). Ct-2, the blue-stained fibrous scar was formed in the vehicletreated MI heart. Tr-3, some of the myocyte-like cells (blue arrow heads) were positively stained by both Ki-67 (brown nuclei) and MHC (yellow cytoplasm) specific antibodies in the aFRLM-treated MI hearts. Ct-3, fibrous scar replacement was found throughout the infarct region (Fib). (Color figure available online only.)

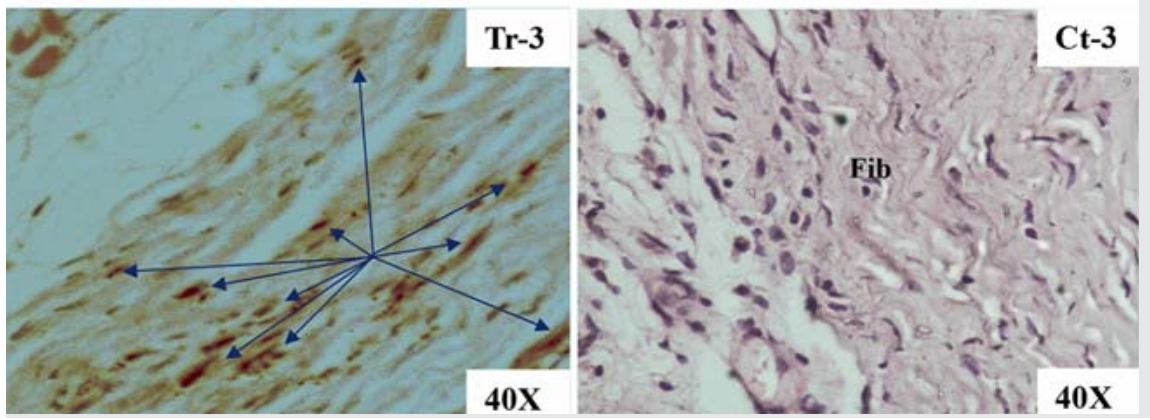

This assumption has been recently tested in our laboratory by treating dermal fibroblasts or CRFs in vitro with a combination of compounds. These treatments could transiently upregulate the expressions of certain cell dedifferentiation-related genes, such as Oct4, c-Myc, Sox2, or Klf4, as well as promote the expression of cardiogenic conversion-associated transcription factors, such as MEF2, GATA4, and TBX5 genes, in treated dermal fibroblasts or CRFs with some beating myocytes of rat-tail-derived fibroblast origin observed [15]. More importantly and consistently, when rats with chronic MI were treated with the combination of compounds, myocardial conversion of the fibroblast in the scar region was observed with the global cardiac function significantly improved [15].

Taken together, we have provided examples of natural plant extracts or compounds, such as R. glutinosa (RGE), ginseng (e.g., Rg1 and Rb1), S. miltiorrhiza Bunge (e.g., tan IIA, salvianolic acid A and salvianolic acid B), G. japonicum Thunb. vax. chinense F. Bolle (e.g., EGJ, AFGJ, and cardiogenin), R. laevigata Michx fruit (e.g., aFRLM), and compound combinations for conversion of CRFs. These treatments can promote angiogenesis, prevent myocyte apoptosis, enhance the proliferation, migration, cardiogenic differentiation, and cardiogenic conversion of EPCs, MSCs, and CRFs for the treatment of CVD. Many other natural products are found to possess similar properties as well. For instance, Xiongshao Capsule, extracted from Rhizoma Ligusticum Wallichii and Radix Paeonia Rubra, can promote angiogenesis via upregulating VEGF and basic fibroblast growth factor (bFGF) expressions [118]. YiQiFuMai injection, a Chinese medicine with ginsenosides as its major constituents, was reported to exert cardioprotective effects to treat chronic heart failure [119]. Shuanglong formula (SLF), a Chinese medicine composed of $P$. ginseng and $S$. miltiorrhiza, was reported to have a therapeutic effect on MI in clinical practice. SLF was further simplified through a bioactivity-guided screening to finally attain a minimized composition (new formula NSLF6) while maintaining its therapeutic effect for MI. It was found that the administration of NSLF6 for the treatment of MI resulted in synergistic therapeutic efficacies between total ginsenosides and total salvianolic acids, probably due to its actions in promoting cardiac cell regeneration, therapeutic angiogenesis, and antagonizing myocyte oxidative damage [120]. It should be noted that a single compound that targets a single gene or gene product may not be sufficient to elicit a curative treatment for most CVDs since the pathology-modifying treatment of a disease, MI for example, involves especially complicated multifactor coordinated processes. However, a rational combination of compounds with their respective activities may achieve a curative treatment effect through a well-coordinated synergistic mechanism.

\section{Conclusions}

$\nabla$

1. Under physiological conditions of an adult human life, the regeneration rate of myocytes through mechanisms of inherited cardiac regeneration during cardiac homeostasis accounts for 
the loss of $\sim 3 \times 10^{6}$ myocytes per day, which is, however, severely limited in pathological cardiac repair [15].

2. Cardiovascular beneficial effects of the application of some natural plant compounds, such as $R$. glutinosa-derived RGE, ginseng-derived ginsenosides ( $\operatorname{Rg} 1, \mathrm{Rb} 1)$, S. miltiorrhiza Bungederived tan IIA, salvianolic acid A and salvianolic acid B, G. japonicum Thunb. vax. chinense F. Bolle-derived EGJ, AFGJ, and cardiogenin, $R$. laevigata Michx fruit-derived aFRLM, and active compound combinations, to enhance mechanisms of inherited cardiac regeneration include promoting angiogenesis, preventing myocyte apoptosis, enhancing the proliferation, migration, and cardiogenic differentiation of the progenitor cells and cardiogenic conversion of EPCs and CRFs.

3. Although previous studies have provided promising evidence of natural plant compounds to enhance mechanisms of inherited cardiac regeneration for the treatment of CVD, future studies in this field should focus more efforts on the isolation of the single compound possessing a particular activity contained in the active fraction or extract of the plant and on the elucidation of the underlying mechanism of a particular action of such a compound, so that a single compound with a specific activity or compound combination with desired multiple activities that are required for curative treatment of a particular disease can be developed.

\section{Acknowledgements}

$\nabla$

This work was supported by a Natural Science Foundation of China grant (81373625) and a private donation (470707).

\section{Conflict of Interest}

$\nabla$

The authors claim no conflicts of interest.

\section{References}

1 Duncan AK, Vittone J, Fleming KC, Smith HC. Cardiovascular disease in elderly patients. Mayo Clin Proc 1996; 71: 184-196

2 Go AS, Mozaffarian D, Roger VL, Benjamin EJ, Berry JD, Blaha MJ, Dai S, Ford ES, Fox CS, Franco S, Fullerton HJ, Gillespie C, Hailpern SM, Heit JA, Howard VJ, Huffman MD, Judd SE, Kissela BM, Kittner SJ, Lackland DT, Lichtman JH, Lisabeth LD, Mackey RH, Magid DJ, Marcus GM, Marelli A, Matchar DB, McGuire DK, Mohler ER, Moy CS, Mussolino ME, Neumar $R W$, Nichol G, Pandey DK, Paynter NP, Reeves MJ, Sorlie PD, Stein J, Towfighi A, Turan TN, Virani SS, Wong ND, Woo D, Turner MB. Executive summary: heart disease and stroke statistics-2014 update: a report from the American Heart Association. Circulation 2014; 129: 399-410

3 Mendis S, Puska P, Norrving B. Global atlas on cardiovascular disease prevention and control. Geneva: World Health Organization; 2011

4 National Heart Lung and Blood Institute. Morbidity \& mortality: 2012 chart book on cardiovascular, lung, and blood diseases. Bethesda: National Institutes of Health; 2012

5 Rosenstrauch D, Poglajen G, Zidar N, Gregoric ID. Stem cell therapy for ischemic heart failure. Tex Heart Inst J 2005; 32: 339-347

6 Kocher AA, Schuster MD, Szabolcs MJ, Takuma S, Burkhoff D, Wang J, Homma S, Edwards NM, Itescu S. Neovascularization of ischemic myocardium by human bone-marrow-derived angioblasts prevents cardiomyocyte apoptosis, reduces remodeling and improves cardiac function. Nat Med 2001; 7: 430-436

7 Lietz K, Long JW, Kfoury AG, Slaughter MS, Silver MA, Milano CA, Rogers JG, Naka Y, Mancini D, Miller LW. Outcomes of left ventricular assist device implantation as destination therapy in the post-REMATCH era. Circulation 2007; 116: 497-505

8 Westfall MV, Pasyk KA, Yule DI, Samuelson LC, Metzger JM. Ultrastructure and cell-cell coupling of cardiac myocytes differentiating in embryonic stem cell cultures. Cell Motil Cytoskeleton 1998; 36: 43-54
9 Min JY, Yang Y, Converso KL, Liu L, Huang Q Morgan JP, Xiao YF. Transplantation of embryonic stem cells improves cardiac function in postinfarcted rats. J Appl Physiol 2002; 92: 288-296

10 Yoshida Y, Yamanaka S. iPS cells: a source of cardiac regeneration. J Mol Cell Cardiol 2010; 50: 327-332

11 Lin B, Kim J, Li YX, Pan HY, Carvajal-Vergara X, Salama G, Cheng T, Li Y, Lo $C W$, Yang $L$. High-purity enrichment of functional cardiovascular cells from human iPS cells. Cardiovasc Res 2012; 95: 327-335

12 Mangi AA, Noiseux N, Kong D, He H, Rezvani M, Ingwall JS, Dzau VJ. Mesenchymal stem cells modified with Akt prevent remodeling and restore performance of infarcted hearts. Nat Med 2003; 9: 1195-1201

13 Cheng L, Chen H, Yao X, Qi G, Liu H, Lee K, Lee K, Zhang J, Chen S, Lin X, Zhao W, Li J, Li M. A plant-derived remedy for repair infarcted heart. PLoS One 2009; 4: e4461

14 Martin-Puig S, Fuster V, Torres M. Heart repair: from natural mechanisms of cardiomyocyte production to the design of new cardiac therapies. Ann N Y Acad Sci 2012; 1254: 71-81

$15 \mathrm{Li} \mathrm{M}, \mathrm{Ng}$ SC. Potentiating the naturally occurring process for repair of damaged heart. Curr Pharm Des 2013; 20: 1950-1963

16 Engel FB. Cardiomyocyte proliferation: a platform for mammalian cardiac repair. Cell Cycle 2005; 4: 1360-1363

17 Bergmann O, Bhardwaj RD, Bernard S, Zdunek S, Barnabé-Heider F, Walsh S, Zupicich J, Alkass K, Buchholz BA, Druid H, Jovinge S, Frisén J. Evidence for cardiomyocyte renewal in humans. Science 2009; 324: 98-102

18 Laflamme MA, Murry CE. Heart regeneration. Nature 2011; 473: 326335

19 Koudstaal S, Jansen Of Lorkeers SJ, Gaetani R, Gho JM, van Slochteren FJ, Sluijter JP, Doevendans PA, Ellison GM, Chamuleau SA. Concise review: heart regeneration and the role of cardiac stem cells. Stem Cells Transl Med 2013; 2: 434-443

20 Poss KD, Wilson LG, Keating MT. Heart regeneration in zebrafish. Science 2002; 298: 2188-2190

21 Jopling C, Sleep E, Raya M, Martí M, Raya A, Izpisúa Belmonte JC. Zebrafish heart regeneration occurs by cardiomyocyte dedifferentiation and proliferation. Nature 2010; 464: 606-609

22 Ausoni S, Sartore S. From fish to amphibians to mammals: in search of novel strategies to optimize cardiac regeneration. J Cell Biol 2009; 184: 357-364

23 Porrello ER, Mahmoud AI, Simpson E, Hill JA, Richardson JA, Olson EN, Sadek HA. Transient regenerative potential of the neonatal mouse heart. Science 2011; 331: 1078-1080

24 Morkin E, Ashford TP. Myocardial DNA synthesis in experimental cardiac hypertrophy. Am J Physiol 1968; 215: 1409-1413

25 Petersen RO, Baserga R. Nucleic acid and protein synthesis in cardiac muscle of growing and adult mice. Exp Cell Res 1965; 40: 340-352

26 Yoshizumi M, Lee WS, Hsieh CM, Tsai JC, Li J, Perrella MA, Patterson C, Endege WO, Schlegel R, Lee ME. Disappearance of cyclin A correlates with permanent withdrawal of cardiomyocytes from the cell cycle in human and rat hearts. J Clin Invest 1995; 95: 2275-2280

27 Urbanek K, Quaini F, Tasca G, Torella D, Castaldo C, Nadal-Ginard B, Leri A, Kajstura J, Quaini E, Anversa P. Intense myocyte formation from cardiac stem cells in human cardiac hypertrophy. Proc Natl Acad Sci U S A 2003; 100: 10440-10445

28 Urbanek K, Torella D, Sheikh F, De Angelis A, Nurzynska D, Silvestri F, Beltrami CA, Bussani R, Beltrami AP, Quaini F, Bolli R, Leri A, Kajstura J, Anversa $P$. Myocardial regeneration by activation of multipotent cardiac stem cells in ischemic heart failure. Proc Natl Acad Sci U S A 2005; 102: 8692-8697

29 Bergmann O, Bhardwaj RD, Bernard S, Zdunek S, Barnabé-Heider F, Walsh S, Zupicich J, Alkass K, Buchholz BA, Druid H, Jovinge S, Frisén J. Evidence for cardiomyocyte renewal in humans. Science 2009; 324: 98-102

30 Hierlihy AM, Seale P, Lobe CG, Rudnicki MA, Megeney LA. The post-natal heart contains a myocardial stem cell population. FEBS Lett 2002; 530: 239-243

31 Beltrami AP, Barlucchi L, Torella D. Adult cardiac stem cells are multipotent and support myocardial regeneration. Cell 2003; 114: 763-776

32 Oh H, Bradfute SB, Gallardo TD, Nakamura T, Gaussin V, Mishina Y, Pocius J, Michael LH, Behringer RR, Garry DJ, Entman NL, Schneider MD. Cardiac progenitor cells from adult myocardium: homing, differentiation, and fusion after infarction. Proc Natl Acad Sci U S A 2003; 100: 12313-12318

33 Messina E, De Angelis L, Frati G, Morrone S, Chimenti S, Fiordaliso F, Salio M, Battaglia M, Latronico MVG, Coletta M, Vivarelli E, Frati L, Cossu G, 
Giacomello L. Isolation and expansion of adult cardiac stem cells from human and murine heart. Circ Res 2004; 95: 911-921

34 Cai CL, Liang X, Shi Y, Chu PH, Pfaff SL, Chen J, Evans S. Isl1 identifies a cardiac progenitor population that proliferates prior to differentiation and contributes a majority of cells to the heart. Dev Cell 2003; 5: 877889

35 Matsuura K, Nagai T, Nishigaki N, Oyama T, Nishi J, Wada H, Sano M, Toko H, Akazawa H, Sato T, Nakaya H, Kasanuki H, Komuro I. Adult cardiac Sca-1-positive cells differentiate into beating cardiomyocytes. J Biol Chem 2004; 279: 11384-11391

36 Limana F, Bertolami C, Mangoni A, Di Carlo A, Avitabile D, Mocini D, Iannelli P, De Mori R, Marchetti C, Pozzoli O, Gentili C, Zacheo A, Germani A, Capogrossi MC. Myocardial infarction induces embryonic reprogramming of epicardial c-kit (+) cells: role of the pericardial fluid. J Mol Cell Cardiol 2010; 48: 609-618

37 Teyssier-Le Discorde M, Prost S, Nandrot E, Kirszenbaum M. Spatial and temporal mapping of c-kit and its ligand, stem cell factor expression during human embryonic haemopoiesis. Br J Haematol 1999; 107: 247-253

38 Yuan S, Schoenwolf GC. Islet-1 marks the early heart rudiments and is asymmetrically expressed during early rotation of the foregut in the chick embryo. Anat Rec 2000; 260: 204-207

39 Bu L, Jiang X, Martin-Puig S, Caron L, Zhu S, Shao Y, Roberts DJ, Huang PL, Domian IJ, Chien KR. Human ISL1 heart progenitors generate diverse multipotent cardiovascular cell lineages. Nature 2009; 460: 113-117

40 Limana F, Zacheo A, Mocini D, Mangoni A, Borsellino G, Diamantini A, Mori RD, Battistini L, Vigna E, Santini M, Loiaconi V, Pompilio G, Germani A, Capogrossi MC. Identification of myocardial and vascular precursor cells in human and mouse epicardium. Circ Res 2007; 101: 1255-1265

41 Di Meglio F, Castaldo C, Nurzynska D, Romano V, Miraglia R, Montagnani $S$. Epicardial cells are missing from the surface of hearts with ischemic cardiomyopathy: a useful clue about the self renewal potential of the adult human heart? Int J Cardiol 2010; 145: e44-e46

42 Wang X, Hu Q Nakamura Y, Lee J, Zhang G, From AH, Zhang J. The role of the sca-1+/CD31-cardiac progenitor cell population in postinfarction left ventricular remodeling. Stem Cells 2006; 24: 1779-1788

43 Dawn B, Stein $A B$, Urbanek $K$, Rota $M$, Whang B, Rastaldo D, Torella D, Tang XL, Rezazadeh A, Kajstura J, Leri A, Hunt G, Vaema J, Prabhu SD, Anversa $P$, Bolli $R$. Cardiac stem cells delivered intravascularly traverse the vessel barrier, regenerate infarcted myocardium, and improve cardiac function. Proc Natl Acad Sci U S A 2005: 102: 3766-3771

44 Zhang GJ, Ji JY, Liu Q, Zhang LH, Gong GY, Jin ZX, Ren SZ. Collected edition of identification and assessment of common TCD. Harbin, China: Heilongjiang SciTech Press; 1993: 301-302

45 Zhang RX, Li MX, Jia ZP. Rehmannia glutinosa: review of botany, chemistry and pharmacology. J Ethnopharmacol 2008; 117: 199-214

46 Zhang YG, Zhang HG, Zhang GY, Fan JS, Li XH, Liu YH, Li SH, Lian XM, Tang $Z$. Panax notoginseng saponins attenuate atherosclerosis in rats by regulating the blood lipid profile and an anti-inflammatory action. Clin Exp Pharmacol Physiol 2008; 35: 1238-1244

47 Liu FJ, Cheng JP, Ru XB, Feng XW, Gu GM. Effect of Rehmannia glutinosa polysaccharides on hematogenesis in mice. Chin J Pham Toxicol 1994; 8: 118

48 Wang YB, Liu YF, Lu XT, Yan FF, Wang B, Bai WW, Zhao YX. Rehmannia glutinosa extract activates endothelial progenitor cells in a rat model of myocardial infarction through a SDF- $1 \alpha /$ CXCR 4 cascade. PLoS One 2013; 8: e54303

49 Chae HJ, Kim HR, Kim DS, Woo ER, Cho YG, Chae SW. Saeng-Ji-Hwang has a protective effect on adriamycin-induced cytotoxicity in cardiac muscle cells. Life Sci 2005; 76: 2027-2042

50 Attele AS, Wu JA, Yuan CS. Ginseng pharmacology: multiple constituents and multiple actions. Biochem Pharmacol 1999; 58: 1685-1693

51 Lee FC. Facts about ginseng: the elixir of life. Elizabeth, NJ, USA: Hollym Int Corp; 1992

$52 \mathrm{Chu} S F$, Zhang JT. New achievements in ginseng research and its future prospects. Chin J Integr Med 2009; 15: 403-408

53 Bahrke MS, Morgan WP. Evaluation of the ergogenic properties of ginseng. Sports Med 1994; 18: 229-248

54 Zeng F, Wang XM, Yang M, Lu ZQ Guo DA. Fingerprint analysis of different Panax herbal species by HPLC-UV method. J Chin Pharmaceut Sci 2007; 16: 277-281

55 Jia L, Zhao Y, Liang XJ. Current evaluation of the millennium phytomedicine-ginseng (II): Collected chemical entities, modern pharmacology, and clinical applications emanated from traditional Chinese medicine. Curr Med Chem 2009; 16: 2924-2942
56 Karmazyn M, Moey M, Gan XT. Therapeutic potential of ginseng in the management of cardiovascular disorders. Drugs 2011; 71: 1989-2008

57 Leung KW, Pon YL, Wong RN, Wong AS. Ginsenoside-Rg1 induces vascular endothelial growth factor expression through the glucocorticoid receptor-related phosphatidylinositol 3-kinase/Akt and beta-catenin/Tcell factor-dependent pathway in human endothelial cells. J Biol Chem 2006; 281: 36280-36288

58 Liang HC, Chen CT, Chang Y, Huang YC, Chen SC, Sung HW. Loading of a novel angiogenic agent, ginsenoside Rg1 in an acellular biological tissue for tissue regeneration. Tissue Eng 2005; 11: 835-846

59 Sengupta S, Toh SA, Sellers LA, Skepper JN, Koolwijk P, Leung HW, Yeung $H W$, Wong RN, Sasisekharan R, Fan TP. Modulating angiogenesis: the yin and the yang in ginseng. Circulation 2004; 110: 1219-1225

60 Chan LS, Yue PY, Mak NK, Wong RN. Role of microRNA-214 in ginsenoside-Rg1-induced angiogenesis. Eur J Pharm Sci 2009; 38: 370-377

61 Chan LS, Yue PY, Wong YY, Wong RN. MicroRNA-15b contributes to ginsenoside-Rg1-induced angiogenesis through increased expression of VEGFR-2. Biochem Pharmacol 2013; 86: 392-400

62 Wang XD, Gu TX, Shi EY, Lu CM, Wang C. Effect and mechanism of panaxoside $\operatorname{Rg} 1$ on neovascularization in myocardial infarction rats. Chin J Integr Med 2010; 16: 162-166

63 Zhang YJ, Zhang XL, Li MH, Iqbal J, Bourantas CV, Li JJ, Su XY, Muramatsu $T$, Tian NL, Chen SL. The ginsenoside Rg1 prevents transverse aortic constriction-induced left ventricular hypertrophy and cardiac dysfunction by inhibiting fibrosis and enhancing angiogenesis. J Cardiovasc Pharmacol 2013; 62: 50-57

64 Zhang ZL, Fan Y, Liu ML. Ginsenoside Rg1 inhibits autophagy in H9c2 cardiomyocytes exposed to hypoxia/reoxygenation. Mol Cell Biochem 2012; 365: 243-250

65 Zhu D, Wu L, Li CR, Wang XW, Ma YJ, Zhong ZY, Zhao HB, Cui J, Xun SF, Huang $X L$, Zhou $Z$, Wang $S Q$. Ginsenoside Rg1 protects rat cardiomyocyte from hypoxia/reoxygenation oxidative injury via antioxidant and intracellular calcium homeostasis. J Cell Biochem 2009; 108: 117-124

66 Wu Y, Xia ZY, Dou J, Zhang L, Xu JJ, Zhao B, Lei S, Liu HM. Protective effect of ginsenoside $\mathrm{Rb} 1$ against myocardial ischemia/reperfusion injury in streptozotocin-induced diabetic rats. Mol Biol Rep 2010; 38: 43274335

67 Kong HL, Li ZQ Zhao YJ, Zhao SM, Zhu L, Li T, Fu Y, Li HJ. Ginsenoside Rb1 protects cardiomyocytes against $\mathrm{CoCl}$-induced apoptosis in neonatalrats by inhibiting mitochondria permeability transition pore opening. Acta Pharmacol Sin 2010; 31: 687-695

68 Guan $L$, Li W, Liu Z. Effect of ginsenoside-Rb1 on cardiomyocytes apoptosis after ischemia and reperfusion in rats. J Huazhong Univ Sci Technolog Med Sci 2002; 22: 212-215

69 Wang XF, Liu XJ, Zhou QM, Du J, Zhang TL, Lu YY, Su SB. Ginsenoside rb1 reduces isoproterenol-induced cardiomyocytes apoptosis in vitro and in vivo. Evid Based Complement Alternat Med 2013; 2013: 454389

70 Li CY, Deng W, Liao XQ Deng J, Zhang YK, Wang DX. The effects and mechanism of ginsenoside Rg1 on myocardial remodeling in an animal model of chronic thromboembolic pulmonary hypertension. Eur J Med Res 2013; 18: 16

71 Wang Z, Li M, Wu WK, Tan HM, Geng DF. Ginsenoside Rb1 preconditioning protects against myocardial infarction after regional ischemia and reperfusion by activation of phosphatidylinositol-3-kinase signal transduction. Cardiovasc Drugs Ther 2008; 22: 443-452

72 Yin H, Liu Z, Li F, Ni M, Wang B, Qiao Y, Xu X, Zhang M, Zhang J, Lu H, Zhang $Y$. Ginsenoside- $\operatorname{Rg} 1$ enhances angiogenesis and ameliorates ventricular remodeling in a rat model of myocardial infarction. J Mol Med 2011; 89: 363-375

73 Zhao H, Lv D, Zhang W, Dong W, Feng J, Xiang Z, Huang L, Oin C, Zhang L. Ginsenoside-Rb1 attenuates dilated cardiomyopathy in $\mathrm{cTnT}(\mathrm{R} 141 \mathrm{~W})$ transgenic mouse. J Pharmacol Sci 2010; 112: 214-222

74 Ji X, Tan BK, Zhu YC, Linz W, Zhu YZ. Comparison of cardioprotective effects using ramipril and DanShen for the treatment of acute myocardial infarction in rats. Life Sci 2013; 73: 1413-1426

75 Cheng TO. Danshen: a versatile Chinese herbal drug for the treatment of coronary heart disease. Int J Cardiol 2005; 113: 437-438

76 Li K, Li SZ, Zhang YL, Wang XZ. The effects of danshen root on cardiomyogenic differentiation of human placenta-derived mesenchymal stem cells. Biochem Biophys Res Commun 2011; 415: 147-151

77 Yin Y, Guan Y, Duan J, Wei G, Zhu Y, Quan W, Guo C, Zhou D, Wang Y, Xi $M$, Wen A. Cardioprotective effect of Danshensu against myocardial ischemia/reperfusion injury and inhibits apoptosis of H9c2 cardiomyocytes via Akt and ERK1/2 phosphorylation. Eur J Pharmacol 2013; 699: $219-226$ 
78 Zhou L, Zuo Z, Chow MS. Danshen: an overview of its chemistry, pharmacology, pharmacokinetics, and clinical use. J Clin Pharmacol 2005; 245: $1345-1359$

79 Wang X, Morris-Natschke SL, Lee KH. New developments in the chemistry and biology of the bioactive constituents of Tanshen. Med Res Rev 2007; 27: 133-148

80 Fu J, Huang H, Liu J, Pi R, Chen J, Liu P. Tanshinone IIA protects cardiaC myocytes against oxidative stress-triggered damage and apoptosis. Eur J Pharmacol 2007; 568: 213-221

81 Gao S, Liu Z, Li H, Little PJ, Liu P, Xu S. Cardiovascular actions and therapeutic potential of tanshinone IIA. Atherosclerosis 2012; 220: 3-10

$82 \mathrm{Xu} \mathrm{W}$, Yang $J$, Wu LM. Cardioprotective effects of tanshinone IIA on myocardial ischemia injury in rats. Pharmazie 2009; 64: 332-336

83 Yang R, Liu A, Ma X, Li L, Su D, Liu J. Sodium tanshinone IIA sulfonate protects cardiomyocytes against oxidative stress-mediated apoptosis through inhibiting JNK activation. J Cardiovasc Pharmacol 2008; 51: 396-401

84 Feng J, Li SS, Liang QS. Effects of Tanshinone II A on the myocardial apoptosis and the miR-133 levels in rats with heart failure. Zhongguo Zhong Xi Yi Jie He Za Zhi 2012; 32: 930-933

85 Zhang L, Wu Y, Li Y, Xu CQ Li XL, Zhu D, Zhang Y, Xing S, Wang HY, Zhang $Z H$, Shan HL. Tanshinone IIA improves miR-133 expression through MAPK ERK1/2 pathway in hypoxic cardiac myocytes. Cell Physiol Biochem 2012; 30: 843-852

86 Gao J, Yang G, Pi R, Li R, Wang P, Zhang H, Le K, Chen S, Liu P. Tanshinone IIA protects neonatal rat cardiomyocytes from adriamycin-induced apoptosis. Transl Res 2008; 151: 79-87

87 Shan H, Li X, Pan Z, Zhang L, Cai B, Zhang Y, Xu C, Chu W, Qiao G, Li B, Lu Y, Yang $B$. Tanshinone IIA protects against sudden cardiac death induced by lethal arrhythmias via repression of microRNA-1. Br J Pharmacol 2009; 158: 1227-1235

88 Zhang Y, Zhang L, Chu W, Wang B, Zhang J, Zhao M, Li X, Li B, Lu Y, Yang B, Shan $H$. Tanshinone IIA inhibits miR-1 expression through p 38 MAPK signal pathway in post-infarction rat cardiomyocytes. Cell Physiol Biochem 2010; 26: 991-998

89 Tong $Y, X u$ W, Han $H$, Chen $Y$, Yang J, Qiao H, Hong D, Wu Y, Zhou C. Tanshinone IIA increases recruitment of bone marrow mesenchymal stem cells to infarct region via up-regulating stromal cell-derived factor-1/ CXC chemokine receptor 4 axis in a myocardial ischemia model. Phytomedicine 2011; 18: 443-450

90 Xie J, Wang H, Song T, Wang Z, Li F, Ma J, Chen J, Nan Y, Yi H, Wang W. Tanshinone IIA and astragaloside IV promote the migration of mesenchymal stem cells by up-regulation of CXCR4. Protoplasma 2013; 250: 521-530

91 Li YJ, Duan CL, Liu JX. Salvianolic acid A promotes the acceleration of neovascularization in the ischemic rat myocardium and the functions of endothelial progenitor cells. J Ethnopharmacol 2014; 151: 218-227

92 Lay IS, Hsieh CC, Chiu JH, Shiao MS, Lui WY, Wu CW. Salvianolic acid B enhances in vitro angiogenesis and improves skin flap survival in Sprague-Dawley rats. J Surg Res 2003; 115: 279-285

93 Lay IS, Chiu JH, Shiao MS, Lui WY, Wu CW. Crude extract of Salvia miltiorrhiza and salvianolic acid $B$ enhance in vitro angiogenesis in murine SVR endothelial cell line. Planta Med 2003; 69: 26-32

94 Li M, Yu CM, Cheng L, Wang M, Gu X, Lee KH, Wang T, Sung YT, Sanderson $J E$. Repair of infarcted myocardium by an extract of Geum japonicum with dual effects on angiogenesis and myogenesis. Clin Chem 2006; 52: $1460-1468$

95 Cheng WH, Cheng $L, G u$ XM, Li M. The dual actions of angiogenesis and anti-apoptosis induced by an isolated compound from Geum japonicum repair muscle ischemia. Arch Biochem Biophys 2007; 459: 91-97

96 Chen H, Peng P, Cheng L, Lin X, Chung SSW, Li M. Reconstitution of coronary vasculature in ischemic hearts by plant-derived angiogenic compounds. Int J Cardiol 2012; 156: 148-155

97 Chen H, Cheng L, Lin XL, Zhou X, Cai M, Li M. Reconstitution of coronary vasculature by an active fraction of Geum japonicum in ischemic hearts. Sci Rep 2014; 4: 3962

98 Cheng L, Gu X, Sanderson JE, Wang X, Lee K, Yao X, Liu H, Cheung WL, Li M. A new function of a previously isolated compound that stimulates activation and differentiation of myogenic precursor cells leading to efficient myofiber regeneration and muscle repair. Int J Biochem Cell Biol 2006; 38: 1123-1133

99 Lin X, Peng P, Cheng L, Chen S, Li K, Li ZY, Mo YH, Zhou Z, Li M. A natural compound induced cardiogenic differentiation of endogenous MSCs for repair of infarcted heart. Differentiation 2012; 83: 1-9
100 Quaini F, Urbanek K, Beltrami AP, Finato N, Beltrami CA, Nadal-Ginard $B$, Kajstura J, Leri A, Anversa P. Chimerism of the transplanted heart. N Engl J Med 2002; 346: 5-15

101 Schwartz RS, Curfman GD. Can the heart repair itself? N Engl J Med 2002; 346: 2-4

102 Dai W, Hale SL, Martin BJ, Kuang JQ Dow JS, Wold LE, Kloner RA. Allogeneic mesenchymal stem cell transplantation in postinfarcted rat myocardium short- and long-term effects. Circulation 2005; 112: 214-223

103 Rafii S, Heissig B, Hattori K. Efficient mobilization and recruitment of marrow-derived endothelial and hematopoietic stem cells by adenoviral vectors expressing angiogenic factors. Gene Ther 2002; 9: 631-641

104 Trounson $A$. The production and directed differentiation of human embryonic stem cells. Endocr Rev 2006; 27: 208-219

$105 \mathrm{Wu}$ Y, Chen L, Scott PG, Tredget EE. Mesenchymal stem cells enhance wound healing through differentiation and angiogenesis. Stem Cells 2007; 25: 2648-2659

106 Liu YT, Lu BN, Xu LN, Yin LH, Wang XN, Peng JY, Liu KX. The antioxidant activity and hypolipidemic activity of the total flavonoids from the fruit of Rosa laevigata Michx. Nat Sci 2010; 2: 175-183

107 Li X, Cao W, Shen Y, Li N, Dong XP, Wang KJ, Cheng YX. Antioxidant compounds from Rosa laevigata fruits. Food Chem 2012; 130: 575-580

108 Toma C, Pittenger MF, Cahill KS, Byrne BJ, Kessler PD. Human mesenchymal stem cells differentiate to a cardiomyocyte phenotype in the adult murine heart. Circulation 2002; 105: 93-98

109 Amado LC, Saliaris AP, Schuleri KH, St John M, Xie JS, Cattaneo S, Durand DJ, Fitton T, Kuang JQ Stewart G, Lehrke S, Baumgartner WW, Martin BJ, Heldman AW, Hare JM. Cardiac repair with intramyocardial injection of allogeneic mesenchymal stem cells after myocardial infarction. Proc Natl Acad Sci U S A 2005; 102: 11474-11479

110 Chen SL, Fang WW, Ye F, Liu YH, Qian J, Shan SJ, Zhang JJ, Chunhua RZ, Liao LM, Lin S, Sun JP. Effect on left ventricular function of intracoronary transplantation of autologous bone marrow mesenchymal stem cell in patients with acute myocardial infarction. Am J Cardiol 2004 94: 92-95

111 Gurtner GC, Werner S, Barrandon Y, Longaker MT. Wound repair and regeneration. Nature 2008; 453: 314-321

112 Singer AJ, Clark RA. Cutaneous wound healing. N Engl J Med 1999 341: 738-746

113 Ieda M, Fu JD, Delgado-Olguin P, Vedantham V, Hayashi Y, Bruneau BG, Srivastava $D$. Direct reprogramming of fibroblasts into functional cardiomyocytes by defined factors. Cell 2010; 142: 375-386

114 van Tuyn J, Pijnappels DA, de Vries AA, de Vries I, van der Velde-van Dijke I, Knaän-Shanzer S, van der Laarse A, Schalij MJ, Atsma DE. Fibroblasts from human postmyocardial infarction scars acquire properties of cardiomyocytes after transduction with a recombinant myocardin gene. FASEB J 2007; 21: 3369-3379

115 Chen JX, Krane M, Deutsch MA, Wang L, Rav-Acha M, Gregoire S, Engels $M C$, Rajarajan K, Karra R, Abel ED, Wu JC, Milan D, Wu SM. Inefficient reprogramming of fibroblasts into cardiomyocytes using Gata4, Mef2c, and Tbx5. Circ Res 2012; 111: 50-55

116 Etzion S, Barbash IM, Feinberg MS, Zarin P, Miller L, Guetta E, Holbova R, Kloner RA, Kedes LH, Leor J. Cellular cardiomyoplasty of cardiac fibroblasts by adenoviral delivery of MyoD ex vivo: an unlimited source of cells for myocardial repair. Circulation 2002; 106: I125-I130

117 Eghbali M, Tomek R, Woods C, Bhambi B. Cardiac fibroblasts are predisposed to convert into myocyte phenotype: specific effect of transforming growth factor beta. Proc Natl Acad Sci U S A 1991; 88: 795-799

118 Lin JM, Zhao JY, Zhuang QC, Hong ZF, Peng J. Xiongshao capsule promotes angiogenesis of HUVEC via enhancing cell proliferation and up-regulating the expression of bFGF and VEGF. Chin J Integr Med 2011; 17: 840-846

119 Xing L, Jiang M, Dong L, Gao J, Hou Y, Bai G, Luo G. Cardioprotective effects of the YiQiFuMai injection and isolated compounds on attenuating chronic heart failure via NF- $k$ B inactivation and cytokine suppression. J Ethnopharmacol 2013; 148: 239-245

120 Liang QL, Liang XP, Wang YM, Xie YY, Zhang RL, Chen X, Gao R, Cheng YJ, Wu J, Xu QB, Xiao QZ, Li X, Lv SF, Fan XM, Zhang HY, Zhang QL, Luo GA. Effective components screening and anti-myocardial infarction mechanism study of the Chinese medicine NSLF6 based on "system to system" mode. J Transl Med 2012; 10: 26 